\title{
In situ study of microstructure in phase transformation of pipe line steel
}

Chen $\mathrm{Gu}^{1}$, Nabil Bassim ${ }^{2}$ and Hatem Zurob ${ }^{3}$

${ }^{1}$ Mcmaster University, Hamilton, Ontario, Canada, ${ }^{2}$ Department of Materials Science and Engineering, McMaster University, Hamilton, Ontario, Canada, Hamilton, Ontario, Canada, ${ }^{3}$ Mcmaster University, United States

High strength low alloy(HSLA) steels with microalloying additions $(<0.1 \%)$ of elements such as $\mathrm{Nb}, \mathrm{Ti}$, $\mathrm{V}$, and $\mathrm{Al}$ are widely used for structural applications such as oil and gas pipelines and automobile components[1]. It is important to understand the kinetics of phase transformations in HSLA to design and obtain an optimal microstructure. Much research analyzes the nucleation and growth of acicular ferrite in low-carbon steel. However, in-situ observations of the phase transformation in HSLA steel are limited [2][3] because of the high temperatures involved. This work is initiated to develop a correlative workflow to analyze the effect of cooling rate on the microstructural features and kinetics of phase transformations in HSLA. We use advanced techniques, such as dynamic laser scanning confocal microscopy (LSCM), EBSD (Electron Back-Scattered Diffraction), FIB(Focused ion beam) and TEM(Transmission Electron Microscopy).

A pipe line steel is used in this study to compare the difference of microstructure at different cooling rates. Direct and dynamic observations in HT(high temperature)-LSCM would allow us to identify the nucleation of ferrite, bainite and martensite depending on cooling rate. It opens the possibility of quickly validating a CCT(continuous-cooling-transformation) diagram and thus fine-tuning of the microstructure for a quick turnaround. Figure 1(a) and (b) shows an example of LSCM images of the steel at different temperatures during $50^{\circ} \mathrm{C} / \mathrm{s}$ cooling rate. The video provided by LSCM shows that Martensite/ bainite is formed around $549^{\circ} \mathrm{C}$ under $50^{\circ} \mathrm{C} / \mathrm{s}$ cooling rate, the final grain size is around 4um. To verify the details of the microstructure post-cooling, subsequent EBSD was conducted to help the identification of grain orientations, and grain size. The sample used in LSCM can be used for EBSD directly without extra sample preparation, as shown in Figure 1(c). Due to the heterogeneity of this real-world sample, studies of the complex details of precipitate nucleation and growth must be local to specific regions within the microstructure. As such, we can choose an area according to the EBSD data. For example, the microstructure in Figure 2(c) contains regions with large misorientation gradients as well as regions with very uniform orientation. A TEM sample is lifted out from each of these areas to conduct detailed analysis. Figure 2(c) shows an example of a precipitate with a diameter of about $50 \mathrm{~nm}$ in the area of Figure 2(a). EDS data in Figures 3(c) and (d), indicate that this is $(\mathrm{Ti}, \mathrm{Nb})(\mathrm{C}, \mathrm{N})$. The results shows that it is possible for us to find precipitates according to the EBSD data.

Detailed study of the density, composition of the precipitates as mapped through correlative microscopy continues to be evaluated. The correlative workflow combination of LSCM, EBSD, FIB and TEM will speed up the feedback loop required to provide steelmakers with valuable information about alloy heterogeneity and thermomechanical processing. 

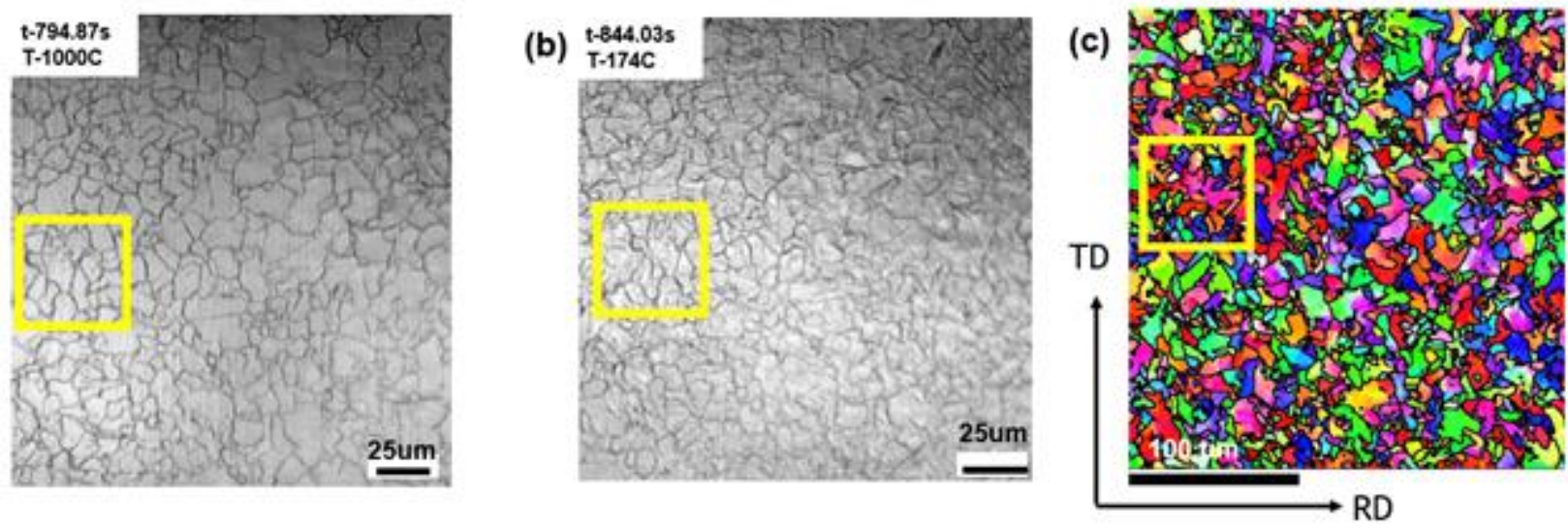

Figure 1. Figure 1. (a): Austenite at $1000^{\circ} \mathrm{C}$ in LSCM;(b) Ferrite and bainite(needle feature within the grain) at $174^{\circ} \mathrm{C}$ in LSCM; (c) EBSD (IPF-Z) data of the same position at LSCM


Figure 2. Figure 2. (a) FIb plan view lift out area (black frame); (b) precipitates in the same area;(c) $\mathrm{Nb}$ distribution of the precipitates in (b); (d) Ti distribution of the precipitates in (b);

\section{References}

[1] Mukherjee, Subrata, et al. Journal of Alloys and Compounds 690 (2017): 621-632.

[2] Lin, Chi-Kang, et al. Ironmaking \& Steelmaking 46.2 (2019): 176-183.

[3] Clark, Samuel, et al. Materials Science Forum. Vol. 879. Trans Tech Publications Ltd, 2017. 